DOI: $10.14451 / 2.137 .36$

\title{
ЧЕЛОВЕЧЕСКИЙ КАПИТАЛ И СОВРЕМЕННЫЕ ТЕНДЕНЦИИ ЕГО РАЗВИТИЯ
}

\author{
(C) 2019 Левченко Лариса Владимировна \\ кандидат экономических наук, доцент \\ Самарский государственный экономический университет, Россия, Самара \\ E-mail: lvls@mail.ru
}

(c) 2019 Карпенко Ольга Анатольевна

кандидат экономических наук, ведущий специалист

АО «СамГЭС» (Самарагорэнергосбыт), Россия, Самара

В работе рассматривается человеческий капитал и его общая структура, а также основные подвиды человеческого капитала: процесс их участия в создании стоимости, их роль в воспроизводственном процессе и природа получаемого дохода. Уделяется внимание проблемам распределения указаных доходов на каждый подвид человеческого капитала. Также отмечаются современные тенденции развития человеческого капитала и его подвидов.

Ключевые слова: человеческий капитал, интеллектуальный капитал, инновационный капитал, социальный, организационный и предпринимательский капитал, духовный капитал, прибыль, предпринимательский доход, рента.

В современной научной литературе проведены разрозненные исследования по вопросам роли и участия некоторых отдельных подвидов человеческого капитала в воспроизводственном процессе и создании стоимости, к примеру, интеллектуального или предпринимательского капиталов человека [1]. При этом не такое заметное внимание уделено исследованию функционирования отдельных подвидов человеческого капитала, к примеру, роли социального капитала или организационного капиталов человека в экономике. Комплексное исследование и изучение всех подвидов человеческого капитала в своей совокупности встречается не так часто. В научных публикациях, исследования и программных документах как правило, отдельно рассматриваются структурные компоненты человеческого или интеллектуального капитала, отдельные вопросы их формирования, развития и использования (например, в исследованиях А.Л.Гапоненко, О.Н. Колпакова, А.М.Пронина, И.И.Просвирина, Е.Н. Селезнев, Г.А. Хмелёва) [2], но при этом не с позиции комплексного подхода к исследованию самих подвидов человеческого капитала. Вместе с тем в настоящее время в связи с массовой автоматизацией производственных процессов и переходом человека к роли управляющего и куратора, научный интерес к исследованиям роли человека и его качеств в экономике только возрастает. В связи с этим изучение и сравнительный анализ основных подвидов человеческого капитала в своей совокупности и их производственной роли представляется нам своевременным и актуальным, ведь само человеческое существование в объективной действительности происходит во взаимодействии всех его структурных составляющих и все капиталы в конечном итоге функционируют в едином субъекте - человеке.

Но прежде, чем переходить к предмету исследования, необходимо изначально прояснить вопрос структуры человеческого капитала в рамках «узкого подхода» к его определению - человеческий капитал состоит из отдельных подвидов капитала: интеллектуального и инновационного, социального, предпринимательского, организационного и культурного [3]. В его составе отдельной позицией идет духовный капитал и вокруг него, составляющего ядро человеческого капитала, формируются все остальные подвиды. Духовный капитал (волевые, ценностные, нравственные и принципиальные качества, стремления, мотивы и т.д.) является главенствующей и основополагающей частью человеческого капитала.

Понятие человеческого капитала, следуя парадигме «узкого» подхода к определению понятий человеческого и интеллектуального капиталов, включает в себя сущностные капитальные аспекты - знания, умения, способности, навыки человека, качества, таланты, опыт и связи, здоровье и потенциал, не включая при этом резуль- 
таты и продукты своей деятельности.

Интеллектуальный капитал человека включает в себя стоимость знаний, навыков и способностей, умений, а также духовных качеств (духовный, ментальный и эмоциональный интеллект и др.).

Инновационный капитал человека - стоимость инновационного мышления, стремления и мотивации к изменениям и созданию новшеств, поиска новых знаний, интуиции и др. Он может входить в состав интеллектуального, предпринимательского или организационного капитала [4].

Социальный капитал включает в себя стоимость человеческих связей и отношений, контактов, знакомств, общественных и социальных возможностей, духовных знаний (предчувствия, интуиции, понимания людей и участие в их жизни, а также связанные с этим затраты).

Предпринимательский капитал - это стоимость человеческих предприниматеских знаний, навыков, умений, способностей, опыта и духовных качеств (мотивации, интуиции, предвидения и т.д.)

Организационный капитал - стоимость человеческих организаторских и управленческих знаний, умений, способностей, навыков и талантов и духовных качеств (оптимальности, духовных знаний и принципов). Организационный капитал (капитал руководителей предприятий) еще можно назвать управленческим капиталом. Организационный и управленческий капитал - синонимичные понятия. Организационным капиталом может обладать любой работник, улучшающий, совершенствующий и разрабатывающий организационные процессы. А управленческий капитал связан с руководством и управлением, это капитал людей на руководящих должностях. Управленческий капитал может включать в себя организационный, но также и организационный капитал может включать в себя управленческий в зависимости от того, какие функции выполняются работником. Носителями организационного капитала являются руководящие работники предприятия, административно-управленческий персонал от низшего звена до высшего. При этом управленческая и организационная деятельность - это не труд и не интеллектуальная деятельность (хотя они в ней также присутствуют),- это, главным образом, деятельность по организации всех производственных процессов и человеческих отно- шений. Специфика организационного капитала выражена Дж.Соросом так: «Управление не является работой в обычном смысле этого слова. Это нечто другое. Это принятие на себя риска ... и иной ... объем работы ...» [5].

Каждый рассматриваемый подвид человеческого капитала участвует в воспроизводственном процессе и вносит свой вклад в создание стоимости. Однако это участие является различным по своей природе, человек по-разному применяет те или иные свои способности и, соответсвенно, это приносит ему различные доходы. При этом, как было сказано ранее, в современном мире постоянно возрастает значение и востребованность личных человеческих качеств - духовных, социальных и интеллектуальных. В связи с массовым внедрением искусственного интеллекта человек все более сосредотачивается на отдаче своих духовных и социально-интеллектуальных качеств (оптимистического настроя, высокой мотивации, общей грамотности, интуиции, понимания людей и применения навыков продуктивного общения и др.), особенно в сферах, напрямую связанных с межличностным общением: в образовании, медицине, сфере услуг, социальной и общественной работе. Также все более экономически востребованными становятся культурные качества человека, когда любимое занятие, связанное со своеобразным отдыхом или хобби, превращается в доходное.

Интеллектуальный и инновационный капитал являются основным двигателем, направителем и ключевым фактором производства, а также всякого развития и прогресса. Вместе в этим в настоящее время происходит расширение сферы применения интеллектуальных ресурсов и все более интеллектуальными становятся все сферы жизнедеятельности: в обучении добавляется постоянное обучение, развитие и самосовершенствование; трудовая деятельность заменяется интеллектуальной и инновационной деятельностью; появляется новая сфера генерации знаний, в которой человек применяет навыки инновационного мышления, формирования, выделения и применения новых знаний; к обычному общению добавляется более интеллектуальное общение в сети; общественная и социальная деятельность также интеллектуализируются; и в семейной жизни требуется проявление духовного и эмоционального интеллекта; становится видна необходимость проявления 
интеллектуальных качеств в хобби и занятиях по интересам.

В составе рабочей силы увеличивается доля интеллектуальной составляющей, в связи с чем может быть введена категория «человеческой интеллектуальной силы» - самой способности человека к интеллектуальной деятельности. Сейчас процесс труда (в том числе интеллектуального) все в большей степени переходит к искусственному интеллекту, и процесс человеческого труда трансформируется в интеллектуальную экономическую деятельность, которая становится движущей производительной силой.

Интеллектуальный капитал, или фактор производства «знания» напрямую принимает участие в создании стоимости. А в интеллектуальном прозводстве он является основным фактором производства, непосредственно эту стоимость создающим. При этом создание стоимости с участием фактора знаний происходит двояко: создание новой стоимости новыми знаниями в процессе создания новых продуктов и услуг и перенос стоимости в процессе тиражирования продуктов и услуг, созданных ранее. Человеческая интеллектуальная деятельность в экономике - это деятельность по применению своих знаний ввиду их общественной необходимости и производительности, которая имеет в своем составе абстрактную деятельность (аналог абстрактного труда и предпосылка стоимости) и конкретную деятельность (аналог конкретного труда и предпосылка стоимости потребительной). Знания могут полностью превратиться в нематериальный капитал и затем их реализация происходит уже в рыночных условиях путем установления цены и определенной монополии на них.

В настоящий момент в связи с цифровизацией и внедрением искусственного интеллекта происходит усиление значимости, экономической роли и результативности интеллектуальной деятельности, а также человеческих коммуникационных и духовных качеств вместо затраченного на труд времени, которое уже не может в полной мере считаться мерилом созданной стоимости. И акцент внимания со стоимости смещается на ценность создаваемых продуктов и услуг. А ценность, как известно, может отличаться от затраченных усилий на их создание, и в большей степени зависеть от востребованности этого продукта потребителем и от конъюнктуры рынка. Если товар уникальный, и на него существует жесткий спрос, то его ценность существенно выше стоимости и содержит в себе элемент монополии. Но и без нее ценность товара в большей степени зависит от необходимости товара для общества, и в меньшей - от затраченного труда на его создание.

Интеллектуальный и инновационный капитал в зависимости от того, какую роль в организационной структуре предприятия играет человек как собственник интеллектуального капитала, получает в виде дохода за свой вклад в производство заработную плату или часть прибыли (интеллектуальной ренты в случае мнополизации созданного продукта). Если это заработная плата, а при этом вклад человека в создание нового продукта существенно выше, то возникает противоречие в харатере присвоения интеллектуального дохода: сам доход - прибыль или ренту - присваивает собственник предприятия, а интеллектуал получает меньшую оплату лишь в форме оплаты своего труда. Но противоречия в присвоении интеллектуального дохода не возникает, если интеллектуал входит в руководящий состав компании и получает свою часть прибыли (ренты).

В настоящее время на государственном уровне созданы институты, запускающие процесс присвоения интеллектуалами прибыли или ренты от создаваемых продуктов на основе новых идей или проектов. Это признанное успешным внедрение института самозанятости [6], при котором человек может самостоятельно находить способы заработка и реализации собственных идей и полностью получать свой заработанный доход (прибыль). И институт проектной работы, или проектной деятельности, в которой интеллектуалы как разрабочики новых идей и продуктов, имеют возможность самостоятельно разработать проект создания нового старт-ап - предприятия и собрать команду для его запуска и успешного функционирования, в которой они будут являться полноценными участниками, в том числе и в распределении дохода. Практика проектной деятельности имеет мировую тенденцию и ускоренно распространяется в экономике. Ее также принимают на вооружение ведущие ВУЗы страны в качестве альтернативы защиты дипломов [7]. Наиболее успешно она применяется в сфере проектирования искусственного интеллекта, инженерии, а также социального предпринимательства и проектирования. Сейчас для молодежи пре- 
доставляются возможности разработки новых идей и запуска проектов благодаря созданным площадкам для поиска партнеров, инвесторов (в качестве которых могут выступать различные фонды, правительство, крупные предприятия и холдинговые структуры) и набора сильных команд. Однако, вместе с тем, подобные площадки и институциональные условия функционирования такого инновационного лифта для развития новых компаний еще находятся в процессе своего развития и их недостаточно.

В современных экономических отношениях активно функционирует и социальный капитал. Наряду с этим он особенно активен в отношениях, связанных с социальной работой, благотворительностью и волонтерством его роль в общественно-экономической жизнм настоящий момент возрастает. Социальный капитал участвует в производственных отношениях посредством своей социальной деятельности. Это деятельность как на фирме, так и вне ее, внешняя деятельность. Социальная деятельность на предприятии представляет собой всестороннее общение, участие в корпоративных вечерах и праздниках, социальных программах и мероприятиях, в общественных обсуждениях и инициативах, а также по возможности - участие в рабочей деятельности и жизни других людей. Здесь важно иметь собственное мнение и личную инициативу как в производственных вопросах, например, инновационную инициативу, так в общественных и социальных. Социальная деятельность вне предприятия делится на два вида: общественная социальная деятельность (общественные проекты, клубы, поездки, мероприятия) и личная, включающая семейную, родственную, дружескую (встречи друзей и родственников, семейные советы, сборы). Нередко личное общение дает эффект и в производственной сфере. Чем больше человек принимает участие в перечисленных мероприятиях и общается, тем больше развивается он сам, обогащает свой внутренний мир, расширяет кругозор и в результате увеличивает свои социальные связи и контакты. Если же он игнорирует какое-либо общение или развитие, то тем самым, замедляет свое социальное развитие и упускает новые возможности. Таким образом, в процессе своего общения человек может как увеличивать и накапливать социальные ресурсы, устанавливая и укрепляя взаимосвязи с людьми, так и терять их при потере, обрыве отношений. При этом каждому конкретному человеку принадлежит только его социальный капитал, который является одним из объектов социального взаимодействия и частью общего социального капитала. При этом заметим, что изначально человек развивает социальные ресурсы и только благодаря его участию в экономической деятельности и принесении дохода они становятся социальным капиталом. Развитый социальный капитал усиливает действие других форм человеческого капитала: интеллектуального, предпринимательского, организационного, а также повышает инновационную активность.

Теперь рассмотрим вкратце формирование социального капитала и его функционирование в сфере производства. Первоначально человек, начиная работать на каком-либо предприятии, в процессе трудовой, интеллектуальной деятельности и общения обзаводится знакомыми, друзьями, соратниками и единомышленниками. Появляются общие темы для общения, общая деятельность, которая иногда переходит и за пределы трудовой деятельности. Затем в процессе всестороннего общения формируются социальные связи, знакомства в соседних и смежных компаниях, в корпорациях и крупных структурах. На начальном этапе социальные связи и отношения с людьми представляют собой социальные ресурсы человека. Производственные и рабочие связи могут переплетаться с личностными и семейными, родственными, в результате может выясниться, что кто-то хорошо знает или даже входит в семью одного из сотрудников фирмы, кто-то знает его родственников или друзей.

Когда же социальные отношения непосредственно переходят в экономические и помогают в производственном процессе и создании новой стоимости, они становятся социальным капиталом человека.

Стоимость создается трудом и деятельностью человека. Социальные связи и отношения помогают облегчить человеческий труд, оказать содействие и помощь в деятельности, повысить производительность труда, принять новые организационные и иные решения, получить новое видение чего-либо и т.д., т.е. непосредственно участвуют и помогают в исполнении своей деятельности, и, следовательно, также участвуют в создании стоимости товаров и услуг. В данном случае часть стоимости создается социальной деятельностью и социальными отношениями. 
Здесь социальная деятельность также включает в себя абстрактную деятельность (создающую стоимость) и конкретную (создающую потребительную стоимость).

Далее хорошие социальные связи и устойчивые отношения между человеком и его окружением начинают играть положительную роль. Они помогают в решении жизненных и производственных задач и проблем, в продвижении по службе, поступлении на более высокую должность и получении более высокой заработной платы. Социальный капитал напрямую влияет на увеличение дохода человека, при этом он может существенно увеличивать этот доход в случае перехода на более высокую должность, вхождения в состав собственников предприятия и т.д.

Таким образом, социальный капитал в воспроизводственном процессе выступает катализатором и необходимым институциональным звеном в цепи создания, развития и расширения возможностей для роста человека, предприятия, объединения. Как правило, он тесно связан с финансовым капиталом и обеспечивает инвестиционный доступ к нему для создания и развития компаний, личностного и финансового роста.

В сфере производства участие социального капитала сокрыто в виде одного или комбинации нескольких факторов производства - «труда», «знаний» и «предпринимательства». Доходом на социальный капитал может являться часть заработной платы, прибыли (ренты) и предпринимательского дохода, полученная благодаря своевременному использованию котактов и связей. Отсюда мы видим, что доход на социальный капитал может принимать любую форму и серьезно варьируется в зависимости от каждого человека, от того продуктивного и положительного общения и социально-производственного взаимодействия с людьми, которое он способен отдавать в окружающую среду. Распределение дохода на социальный капитал носит строго адресный характер, т.к. другому человеку его присвоить невозможно, поэтому здесь отсутствует какое-либо противоречие в его присвоении.

Роль социального капитала в современном процессе потребления также возрастает, развивается коллективное потребление благ услуг (каршеринг машин и т.д.). В настоящее время роль социального капитала и общения в экономике еще более возросла и благодаря интер- нет-сети и дает людям новые возможности как для личного развития и роста (большая коммуникабельность и общение с известными и успешными людьми) и преодоления территориальных барьеров, так и для развития новых организаций.

Переходя к рассматриванию предпринимательского капитала, заметим, что его роль в воспроизвосдвтенном процессе - это то, что он служит непосредственным инициатором создания и модиыикаций производства. Доходом на предпринимательский капитал и фактор производства «предпринимательство» служит предпринимательский доходод, но также им может являться прибыль, в том числе рента.

Изначально по своей экономической природе предпринимательский доход является доходом на предпринимательский фактор производства, а прибыль - доходом на капитал, средства производства и наемный труд. Сама по себе прибыль является доходом на капитал как собственность и получается в процессе эксплуатации наемных рабочих. В отличие от нее, предпринимательский доход имеет принципиально иную природу. Он выступает как дополнительная, возведенная в степень, оплата за риск, новаторство, научно-технический прогресс, улучшение организации производства и труда, маркетинг и рекламу,- деятельность предпринимателя. Предпринимательский доход (в чистом виде) не связан с эксплуатацией чужого труда. Он представляет собой вклад предпринимателя или менеджера в создание новой стоимости, в умножение своего и общественного богатства. Отсюда объясняется растущее внимание, которое уделяется сегодня элите предпринимательства, лучшим менеджерам России как создателям новой стоимости. В литературе отмечается, что российская школа экономической мысли еще в конце XIX века четко разделяла прибыль и предпринимательский доход, о чем писали Д. Пихно, И. Иванюков и др. [8]

В настоящее время в связи с усложнением производства и возрастанием роли новаторства и инновационных идей своеобразной разновидностью предпринимательского дохода становится интеллектуальная собственность (патенты, бренды, акции). Но в процессе приватизации о ней, несмотря на предупреждения ученых, забыли или умолчали. Во времена приватизации нематериальный интеллектуальный и предпринимательский капитал просто не учитывался 
при распределении акций. И в результате многие ценные сотрудники предприятий остались без доли собственности в них. Это наглядный пример не столько противоречия в характере присвоения интеллектуального дохода, сколько прямое несанкционированное присвоение чужого дохода.

В настоящее время совпадение в одном лице собственника и предпринимателя встречается редко и характерно для самозанятости, мелкой частной собственности или для начальных этапов становления предпринимательства. Более того, с развитием кредита, акционерных обществ и формированием управленческой структуры такое совпадение является почти исключением. Собственником фирмы зачастую является собственник капитала, а предприниматель и инициатор изменений лишь имеет определенную долю в нем. Таким образом, предприниматель получает совокупный доход, состоящий из дохода на капитал как часть прибыли и свой предпринимательский доход, которые трудно разделить. В основном он получает свою долю прибыли, а предпринимательский доход выступает в форме дополнительного бонуса от нее же. В итоге современный предпринимательский доход, как правило, состоит из прибыли.

В современной экономической теории уже четко не выделяют прибыль предпринимателя и предпринимательский доход. Сам предпринимательский доход в форме прибыли делят на две части, образующие основу нормальной прибыли и экономической прибыли. К первой относят как бы гарантированный доход предпринимателя, представляющий собой нормальную прибыль. Нормальную (или среднюю) прибыль получают те собственники предпринимательского капитала, у которого выручка покрывает затраты с излишком, достаточным для дальнейшего удержания и выживания в отрасли, выплаты премий сотрудникам и развития производства. Ко второй части этого дохода относят плату за риск, новаторство и работу над получением монопольной власти, которая является уже экономической прибылью, а если она избыточна - рентой. Общая величина предпринимательского дохода колеблется за счет этой второй составляющей. По своей природе этот второй доход является чистой экономической прибылью предпринимателя, которая в зависимости от уровня монополизации рынка и возможности удержания этой монополии может принимать форму сверхприбыли и ренты.

Сверхприбыль достается тем предпринимателям, у которых полученный излишек существенно выше расходов на развитие фирмы и выплату премий, и они могут себе позволить запуск новой линии, существенное расширение и модернизацию производства. В данный момент фирма временно оказалась в монопольном сегменте рынка, но окончательно не закрепила свои права на него, или по различным причинам, этого оказалось добиться невозможно.

Предпринимательский доход в виде ренты доступен тем собственникам предпринимательского капитала, которые смогли найти уникальную нишу и закрепить свои монопольные права на реализацию продукта. Но прибыль, полученная предпринимателем на изначально конкурентном рынке, как правило, менее склонна к монополизации и имееет гораздо меньший рентный потенциал по сравнению, например, с интеллектуальной рентой, в связи с тем, что в предпринимательской среде, если это не уникальная рыночная ниша, как правило, более высокая конкуренция, чем в интеллектуальноинновационной сфере. Однако предприниматель, по сравнению с собственноком интеллектуального капитала, сам является собственником производства и получает прибыль. Здесь также отсутствует противоречие в присвоении предпринимательского дохода, будь то сам доход, прибыль или рента, они достаются предпринимателю.

В настоящее время наблюдается возрождение предпринимательской активности, развивается молодежное предпринимательство и социальное проектирование, основной целью которых является решение общественных и социальных проблем, а лишь во воторую очередь получение дохода. Как показывает практика, к такой деятельности привлекается большое количество волонтеров, готовых работать и без вознаграждения, в связи с чем, в данной сфере изначально отсутствует дефицит кадров.

Рассматривая организационный капитал человека, отметим, что он также может участвовать в производстве как один из факторов производства «труд», «знания», «предпринимательство». Доходом на него является заработная плата руководителя или организатора. Заработная плата - это вознаграждение или денежная компенсация за труд и интеллектуальную, организационную, управленческую деятельность или 
Таблица 1. Участие подвидов человеческого капитала в сфере производства

\begin{tabular}{|c|c|c|c|c|}
\hline Подвиды ЧК & ИК & ПК & СК & ОК \\
\hline $\begin{array}{c}\text { Фактор } \\
\text { производства }\end{array}$ & Т, ИК (3) & $\Pi$ & $\begin{array}{c}\text { Т, ИК (3), П, К } \\
\text { (инвестор) }\end{array}$ & Т, ИК (3) \\
\hline Доход & $\begin{array}{c}\text { Заработная плата, } \\
\text { прибыль и рента }\end{array}$ & $\begin{array}{c}\text { Предпринимательский } \\
\text { доход: нормальная прибыль } \\
\text { и экономическая прибыль } \\
\text { (рента) }\end{array}$ & $\begin{array}{c}\text { Заработная плата, } \\
\text { процент на ка- } \\
\text { питал, прибыль и } \\
\text { рента }\end{array}$ & Заработная плата \\
\hline
\end{tabular}

Составлено авторами

службу в зависимости от квалификации работника, сложности, количества, качества и условий его труда и деятельности. Это установленное соглашением систематическое вознаграждение за выполненную работу, деятельность или службу.

Присвоение этого дохода должно происходить строго его создателем - организатором, если его вклад призан в компании. Если же вклад не заметен, недооценен, или присвоен другим сотрудником, когда работает и вкладывает свой труд один человек, а результаты присваивает другой, то также возникает противоречие в характере присвоения дохода.

Организационный капитал, по сравнению с предпринимательским и интеллектуальным, наоборот, в настоящее время переживает определенный кризис развития. Прежде всего, чтобы организационные новшества были оценены и вознаграждены по заслугам, необходимо показать увеличение прибыли, иной выгоды или экономии издержек компании, что требует дополнительных знаний и трансакционных затрат на составление соответствующих отчетов. Успешно и грамотно презентовать себя и свою работу могут не все сотрудники, и зачастую некоторые организаторы работают, не получая адекватного вознаграждения за свой труд.

В современном мире также возрастает роль общения руководителей и предпринимателей, роль процесса передачи их знаний и опыта, однако в связи с более высокой стоимостью и индивидуальностью предпринимательских, организаторских и управленческих знаний, а также с более узкой аудиторией, данный процесс выражен менее ярко, чем та же передача интеллектуально-профессиональных знаний, в отношении которых существует массовая сфера образования, система дополнительного обучения.

Итак, рассмотрев роли основных подвидов человеческого капитала в современном воспроизводственном процеессе и характер получаемых доходов на них, наглядно представим их в виде Таблицы 1.

Заметим, что в современном интеллектуальном и инновационном производстве функция Кобба-Дугласа целиком представляет собой вклад человека или команды людей. Если абстрагироваться от фактора «земли» и предположить, что человек обладает достаточным количеством фактора «капитал», то остальные факторы производства - «труд», «предпринимательство», «интеллектуальный капитал» или «знания» и «информация» так или иначе принадлежат человеку или связаны с его влиянием. И эта тенденция устойчива, т.к. в связи с введением самозанятости человек становится единым субъектом производственного процесса, сосредотачивает в своем лице собственника, предпринимателя и наемного работника, имея в одном лице все факторы производства. Это говорит об углублении тенденции к развитию индивидуальных личностных качеств человека, развитию всевозможных подвидов его человеческого капитала и увеличению возможностей для их применения в экономике.

\section{Библиографический список}

1. Гэлбрейт Дж.Новое индустриальное общество: [пер. с англ.] / Джон Гэлбрейт.- Москва. АСТ; СанктПетербург: Транзиткнига, 2004.-602 с.; Т. А. Стюарт. Интеллектуальный капитал. М.: Поколение, 2007.368 с.; Белл Д. Грядущее постиндустриальное общество. Опыт социального прогнозирования / Д. Белл. - М.: Academia, 1999.- 944 с.; Брукинг Э. Интеллектуальный капитал / Пер. с англ. под ред. Л. Н. Ковалик.- СПб: 2001.- 288 с.; Эдвинссон Л., Мелоун М. Интеллектуальный капитал. Определение истинной стоимости компании // Новая индустриальная волна на Западе.- М.: Academia, 1999; Страссман П. Информация век электроники. Проблемы управления. Пер. с англ., М.: Экономика, 1987.-240 с. 
2. Хмелева Г.А. Человеческий капитал как условие формирования инновационной экономики региона: монография / Г. А. Хмелева; Администрация гор. окр. Самара, Автономное муниципальное образовательное учреждение высш. проф. образования «Самарская акад. гос. и муниципального упр.».- Самара: Изд-во САГМУ, 2012.- 167 с.

3. Левченко Л.В.Интеллектуальный капитал: методологические принципы и методы научного познания// Вестник Омского университета. Серия: Экономика. 2013. № 3. С. 143-147; Левченко Л. В., Карпенко О. А. Теоретические подходы к анализу категории «интеллектуальный капитал»// Экономические науки. 2009.№ 52. - С.64-69.

4. Левченко Л.В., Карпенко О.А. Функционирование и развитие интеллектуального и инновационного капиталов в современной производственной сфере// Экономические науки. 2019. № 181. С.92-94.

5. Сорос Дж. Сорос о Соросе. Опережая перемены: Инфра-М, 1996. - 149 с. - С. 5.

6. Крицккая М. На что могут рассчитывать самозанятые: новые возможности в 2020 году // Журнал Контур. Режим доступа: https://kontur.ru/articles/4818

7. Ганбаров А. Т. Старап вместо дипломной работы // Вестник науки и образования. - 2019. - № 4 .

8. Абалкин Л. И. Логика экономического роста. М.: Институт экономики РАН, 2002-228 с. 